\title{
Studi Eksploratif terhadap Proses Pembelajaran Materi Organogenesis Turunan Mesoderm Matakuliah SPH II di Jurusan Biologi
}

\author{
Muh. Nur Akbar ${ }^{1}$, Mohamad Amin ${ }^{1}$, Umie Lestari ${ }^{1}$ \\ ${ }^{1}$ Pendidikan Biologi-Universitas Negeri Malang
}

\begin{tabular}{l}
\hline \hline INFO ARTIKEL \\
\hline Riwayat Artikel: \\
Diterima: 06-05-2019 \\
Disetujui: 25-05-2019 \\
\hline
\end{tabular}

\section{Kata kunci:}

learning process; difficulty learning; the structure of animal development; proses pembelajaran, kesulitan belajar; struktur perkembangan hewan

\author{
Alamat Korespondensi: \\ Muh. Nur Akbar \\ Pendidikan Biologi \\ Universitas Negeri Malang \\ Jalan Semarang 5 Malang \\ E-mail: mnurakbarabai@gmail.com
}

\begin{abstract}
This study aims to reveal the difficulties faced by students in the learning process at the course of Structure of Animal Development II (SPH II), organogenesis of mesoderm derivatives material. Type of this research is descriptive research conducted at Offering G Biology Study Program, Mathematics and natural science faculty, State University of Malang. Data collection techniques are using observation, interview and questionnaires. The results of the study showed that $88.8 \%$ of students had difficulties in the learning process, $44.4 \%$ of them had difficulty to understand the material and $44.4 \%$ had difficulty to obtain reference. All students expect teaching materials that are equipped with supporting media. The conclusions of this study provide recommendation for developing printed book integrated with technology that can display videos to resolve student difficulties in learning.
\end{abstract}

ABSTRAK

\begin{abstract}
Abstrak: Penelitian ini bertujuan untuk mengungkap kesulitan yang dihadapi mahasiswa dalam proses pembelajaran pada matakuliah Struktur Perkembangan Hewan II (SPH II) materi organogenesis turunan mesoderm. Jenis penelitian adalah penelitian deskriptif yang dilakukan di Offering G Program Studi Biologi FMIPA Universitas Negeri Malang. Teknik pengumpulan data yaitu menggunakan observasi, interview, dan angket kebutuhan mahasiswa. Hasil penelitian menunjukkan bahwa 88,8\% mahasiswa memperoleh kesulitan dalam proses pembelajaran, 44,4\% diantaranya kesulitan memahami materi dan 44,4\% lainnya kesulitan memperoleh sumber rujukan. Seluruh mahasiswa mengharapkan adanya bahan ajar yang dilengkapi dengan media penunjang. Adapun kesimpulan penelitian ini memberikan rekomendasi pengembangan bahan ajar cetak terintegrasi dengan teknologi yang dapat menampilkan gambar bergerak atau video untuk membantu mengatasi kesulitan mahasiswa dalam belajar.
\end{abstract}

Pendidikan tinggi saat ini masih mencari metode yang tepat untuk diterapkan dalam proses pembelajaran. Tuntutan yang tinggi dari dunia kerja atau pasca perkulihan menyebabkan kualitas pendidikan tinggi harus ditingkatkan untuk menciptakan sumber daya manusia yang baik. Tuntutan tersebut tentunya harus mengikuti perkembangan pendidikan tinggi dan pendidikan di abad 21 (Ponomariova \& Vasina, 2016). Pendidikan abad 21 sangat berkaitan dengan perkembangan teknologi dan informasi yang memberikan tantangan terhadap perubahan paradigma pendidikan. Pembelajaran tingkat tinggi diharapkan dapat terjadi lebih interaktif, kolaboratif hingga mampu membangun lingkungan belajarnya sendiri (Perrin, Perrin, Muirhead, \& Betz, 2015). Lingkungan belajar yang baik akan terbentuk jika dosen dapat menstimulus mahasiswa untuk berpikir dan belajar secara mandiri sesuai dalam teori belajar konstruktivisme. Teori konstruktivisme memandang bahwa mahasiswa dapat mengonstruk pengetahuannya sendiri berdasarkan pengalaman yang telah diperoleh sebelumnya (Suyono, 2012).

Hasil observasi dalam proses pembelajaran menggambarkan proses pembelajaran pada topik perkembangan embrio mamalia. Pada proses pembelajaran, konsep penting terkait pembelajaran beberapa tidak dimunculkan oleh mahasiswa saat melakukan diskusi kelas. Sumber belajar yang digunakan oleh mahasiswa, seperti buku elektronik, buku teks, modul, dan petunjuk praktikum belum memberikan pengalaman belajar bagi mahasiswa karena tidak dilengkapi dengan media penunjang yang menggambarkan secara jelas proses-proses yang terjadi dalam perkembangan embrio. Selain itu, mahasiswa mengalami kesulitan dalam menjelaskan proses perkembangan embrio mamalia sehingga harus mencari sumber belajar berupa video secara online. Dosen pengampu juga mengalami kesulitan yang sama saat menjelaskan beberapa konsep yang bersifat abstrak. Kondisi tersebut akan menyulitkan mahasiswa mencapai pemahaman konsep dan tidak menciptakan lingkungan yang maksimal untuk 
belajar. Oleh karena itu, dibutuhkan solusi untuk mengatasi permasalahan yang dihadapi mahasiswa. Salah satu cara yang dapat digunakan yaitu dengan memberikan bahan ajar yang dapat menstimulus belajar mahasiswa.

Bahan ajar yang umum digunakan yaitu bahan ajar cetak yang berfungsi untuk membangkitkan motivasi, dan membangkitkan respon belajar (Setyosari, 2005). Bahan ajar tentunya membutuhkan bantuan media pembelajaran dalam pemanfaatannya agar lebih mencapai fungsi dari bahan ajar tersebut. Media pembelajaran harus selalu mengikuti perkembangan teknologi yang berbasis teknologi cetak, komputer, dan gabungan antara cetak-teknologi. Penggabungan antara teknologi cetak dan komputer telah banyak dikembangkan agar membantu dalam memvisualisasikan objek dalam bentuk gambar, animasi dan atau video. Kebanyakan mahasiswa dapat dengan mudah menerima konsep materi yang didukung oleh visualisasi dari konsep tersebut. Oleh karena itu, alat bantu untuk mempercepat pemahaman mahasiswa yang dibutuhkan yaitu berupa bahan ajar cetak yang diintegrasikan dengan teknologi komputer (Smaldino, Lowther, \& Russell, 2008).

Salah satu bahan ajar cetak yang diitegrasikan dengan teknologi komputer yaitu bahan ajar yang dibantu dengan teknologi augmented reality. Augmented reality merupakan aplikasi yang dapat mengintegrasikan benda maya dalam bentuk yang nyata melalui tampilan di layar smartphone (Azuma, 1997). Belajar menggunakan augmented reality dapat memberikan lingkungan belajar yang menyenangkan (Hueg, 1963). Penggunaan bahan ajar cetak yang terintegrasi dengan komputer perlu didukung melalui penerapan pendekatan yang sesuai. Konsep yang diterima mahasiswa akan terbangun dengan baik melalui pengalamannya berinteraksi secara kontekstual. Melalui aspek kontekstual tersebut, pendekatan yang tepat digunakan yaitu Contextual Teaching and Learning (CTL). Pendekatan CTL menggunakan konteks kehidupan dan lingkungan sekitar mahasiswa untuk belajar dari bahan ajar dan menggunakannya kembali dalam hidupnya dan lingkungannya (Ridwanulloh, Jayadinata, \& Sudin, 2015). Hasil penelitian Bachtiar \& Haryanto (2015) menunjukkan bahwa pemanfaatan augmented reality memberikan hasil positif terhadap hasil belajar mahasiswa.

\section{METODE}

Penelitian dilaksanakan pada semester gasal tahun ajaran 2018/2019. Jenis penelitian ini adalah penelitian deskriptif dalam bentuk survei yang dilakukan di Offering G Program Studi Biologi yang sedang menempuh matakuliah Struktur Perkembangan Hewan II (SPH II) FMIPA Universitas Negeri Malang. Subjek penelitian ini terdiri dari 18 mahasiswa dan satu dosen pengampu. Teknik pengumpulan data dilakukan dengan observasi, wawancara, dan angket kebutuhan mahasiswa.

\section{HASIL}

Pada tahap ini, diperoleh kendala-kendala dalam proses pembelajaran dan kebutuhan mahasiswa akan sumber belajar yang dapat membantu dalam memahami konsep terutama dalam konsep perkembangan embrio mamalia. Adapun hasil observasi, wawancara, dan pengisian angket akan disajikan pada tabel 1, 2, dan 3 .

\section{Tabel 1. Hasil Observasi Proses Perkuliahan SPH II}

\begin{tabular}{cll}
\hline No. & Aspek yang Diamati & \multicolumn{1}{c}{ Hasil Pengamatan } \\
\hline 1. & $\begin{array}{l}\text { Sumber Belajar dan } \\
\text { Media Pembelajaran }\end{array}$ & $\begin{array}{l}\text { 1. Sumber Belajar : Bahan Ajar Cetak, Buku Elektronik, Petunjuk Praktikum, Media LCD Proyektor, dan } \\
\text { Slide Presentasi } \\
\text { 2. Media Pembelajaran : Media Gambar Bergerak (Video) }\end{array}$ \\
\hline 2. & Kegiatan & $\begin{array}{l}\text { Kegiatan pembelajaran dilaksanakan dengan menggunakan metode presentasi dan diskusi. Setiap pertemuan, } \\
\text { Pembelajaran }\end{array}$ \\
& $\begin{array}{l}\text { 1 kelompok mahasiswa mempresentasikan materi pembelajaran dan membuka sesi tanya jawab. Setelah itu, } \\
\text { dosen pengampu memberikan penguatan dan menjawab pertanyaan yang kurang tepat. }\end{array}$ \\
\hline
\end{tabular}

\section{Tabel 2. Hasil Wawancara dengan Dosen Pengampuh Matakuliah SPH II}

\begin{tabular}{cll}
\hline No. & \multicolumn{1}{c}{ Aspek yang Ditanyakan } & \multicolumn{1}{c}{ Jawaban Dosen Pengampuh } \\
\hline 1. & Sumber Belajar yang Digunakan & $\begin{array}{l}\text { Bahan ajar dan sumber belajar yang digunakan yaitu buku teks cetak, buku elektronik berbahasa } \\
\text { Inggris, jurnal hasil penelitian, dan petunjuk praktikum. }\end{array}$ \\
\hline 2. & $\begin{array}{l}\text { Kesulitan Mahasiswa yang Dosen } \\
\text { Pengampuh Amati }\end{array}$ & $\begin{array}{l}\text { Kesulitan mahasiswa yaitu sulit memahami konsep fertilisasi, perkembangan embrio dan } \\
\text { organogenesis dengan alasan karena adanya mekanisme gerak sel, komunikasi sel, gerakan } \\
\text { morfogenetik dan terdapat ekspresi gen dalam prosesnya }\end{array}$ \\
\hline 3. & $\begin{array}{l}\text { Kesulitan Dosen Pengampuh dalam } \\
\text { Mengajar }\end{array}$ & $\begin{array}{l}\text { Dosen pengampuh sulit memberikan penjelasan secara langsung terkait perkembangan embrio } \\
\text { yang sifatnya abstrak dana terdapat mekanisme yang pergerakan sel. Dibutuhkan metode yang } \\
\text { kontekstual sehingga dapat menggambarkan perkembangan embrio secara utuh. }\end{array}$ \\
\hline 4. & $\begin{array}{l}\text { Pendapat Dosen Pengampuh } \\
\text { terhadap Pengembangan Buku } \\
\text { Berbasis Penelitian }\end{array}$ & $\begin{array}{l}\text { Pada prinsipnya dosen pengampuh setuju pada pengembangan buku berbasis penelitian karena } \\
\text { dapat memberikan contoh konkret terkait materi yang ada dalam perkembangan embrio. }\end{array}$
\end{tabular}

5. Hal yang diharapkan Ada dalam Diharapkan dalam buku yang dikembangkan dapat dilengkapi dengan video yang dapat Buku yang Dikembangkan mendukung materi yang ada dalam buku tersebut. 
Tabel 3. Hasil Angket Analisis Kebutuhan oleh Mahasiswa

\begin{tabular}{|c|c|c|c|}
\hline No. & Aspek yang Ditanyakan & Hasil Respon Mahasiswa & Keterangan \\
\hline 1. & $\begin{array}{l}\text { Pendapat Terkait Mata } \\
\text { Kuliah SPH II }\end{array}$ & $\begin{array}{l}\text { 1. Sangat Penting : } 83 \% \\
\text { 2. Penting : } 16.7 \% \\
\text { 3. Tidak penting : } 0\end{array}$ & $\begin{array}{l}\text { Matakuliah SPH II dianggap penting bagi mahasiswa sebagai kompetensi } \\
\text { mereka setelah lulus. }\end{array}$ \\
\hline 2. & $\begin{array}{l}\text { Pemahaman Mahasiswa } \\
\text { terhadap Materi yang } \\
\text { Disampaikan }\end{array}$ & $\begin{array}{l}\text { 1. Paham : } 22,2 \% \\
\text { 2. Sebagian : } 77,8 \% \\
\text { 3. Tidak paham : } 0\end{array}$ & $\begin{array}{l}\text { Sebagian mahasiswa paham karena membaca dan belajar sebelum } \\
\text { perkuliahan dimulai, sedangkan sebagian lainnya tidak mempersiapkan } \\
\text { diri dan sulit memahami buku yang dibaca. }\end{array}$ \\
\hline 3. & $\begin{array}{l}\text { Kesulitan dalam Proses } \\
\text { Pembelajaran }\end{array}$ & $\begin{array}{l}\text { 1. Sulit memahami : } \\
44,4 \% \\
\text { 2. Kesulitan menemukan } \\
\text { sumber rujukan : } 44,4 \% \\
\text { 3. Lainnya : } 11,2 \%\end{array}$ & $\begin{array}{l}\text { Kesulitan yang dialami mahasiswa yaitu tidak memahami materi } \\
\text { pelajaran karena contoh yang diberikan belum konkret, dan kesulitan } \\
\text { dalam memahami sumber rujukan berbahasa inggris. }\end{array}$ \\
\hline 4. & $\begin{array}{l}\text { Cara yang Dilakukan } \\
\text { untuk Mengatasi Kesulitan }\end{array}$ & $\begin{array}{l}\text { 1. Membaca buku atau } \\
\text { buku elektronik : } 40 \% \\
\text { 2. Berdiskusi dengan } \\
\text { teman : } 42,5 \% \\
\text { 3. Bertanya ke dosen : } \\
17,5 \%\end{array}$ & $\begin{array}{l}\text { Mahasiswa memilih berdiskusi dengan teman untuk mengatasi kesulitan } \\
\text { yang mereka alami, kemudian bertanya kepada dosen, lalu membaca buku } \\
\text { elektronik dan sumber belajar lainnya. }\end{array}$ \\
\hline 5. & $\begin{array}{l}\text { Sumber Belajar yang } \\
\text { Digunakan }\end{array}$ & $\begin{array}{l}\text { Sulit menggunakan bahan } \\
\text { ajar } 12 \\
\text { Tidak sulit } 6\end{array}$ & $\begin{array}{l}\text { Sebagian besar mahasiswa masih menganggap sumber belajar yang } \\
\text { mereka gunakan belum mencakup semua materi perkuliahan dan } \\
\text { mengalami kesulitan dengan bahan ajar yang digunakan karena tidak } \\
\text { dilengkapi dengan media pendukung serta berbahasa Inggris. }\end{array}$ \\
\hline 6. & $\begin{array}{l}\text { Sumber Belajar yang } \\
\text { Diharapkan Mahasiswa }\end{array}$ & $\begin{array}{l}\text { Mengharapkan bahan ajar } \\
\text { yang dilengkapi media } \\
\text { pembelajaran }\end{array}$ & $\begin{array}{l}\text { Mahasiswa mengharapkan bahan ajar yang dapat memberikan gambaran } \\
\text { baik terhadap konsep yang bersifat abstrak dan didukung media yang } \\
\text { praktis. }\end{array}$ \\
\hline
\end{tabular}

\section{PEMBAHASAN}

Berdasarkan hasil observasi perkuliahan Struktur Perkembangan Hewan diketahui bahwa proses pembelajaran dilakukan melalui metode presentasi dan diskusi. Presentasi dan diskusi dapat memberikan kesempatan mahasiswa untuk tampil secara profesional dan memberikan motivasi dalam belajar (Hernawati \& Amin, 2017). Metode ini juga memiliki kelebihan yang membuat mahasiswa dapat mengemukakan sebuah konsep secara sistematis hingga mahasiswa mampu menguasai dengan baik konsep tersebut (Rifa'i, 2012). Meskipun demikian, mahasiswa masih memiliki kesulitan dalam proses pembelajaran. Metode presentasi dan diskusi juga memiliki kekurangan yaitu metode ini tidak selalu mampu mencapai tujuan pembelajaran jika mahasiswa memiliki kekurangan dalam berpikir ilmiah dan kekurangan argumentasi lisan. Metode lain perlu diterapkan untuk mencapai tujuan pembelajaran (Mulyasa, 2003). Salah satu metode yang dapat digunakan yaitu Contextual Teaching and Learning (CTL). Pembelajaran kontekstual mampu menghubungkan antara kondisi nyata dengan materi yang diajarkan. Melalui pembelajaran kontekstual, mahasiswa akan termotivasi untuk mampu menerapkan pengetahuan yang diterima dalam kehidupan sehari-hari (Winarti, 2017).

Hasil wawancara dengan dosen pengampu memberikan gambaran bahwa proses pembelajaran perlu dievaluasi. Dosen pengampu memperkuat pernyataan bahwa dibutuhkan metode pembelajaran melalui pendekatan kontekstual agar mampu memberikan pengalaman belajar yang baik pada mahasiswa. Dosen pengampu juga memberikan informasi bahwa bahan ajar yang digunakan mahasiswa belum dilengkapi dengan media yang sesuai untuk menggambarkan konsep perkembangan embrio mamalia secara utuh terutama pada materi organogenesis turunan mesoderm. Mahasiswa cenderung menggunakan internet untuk mencari video pendukung. Proses pembelajaran menjadi rumit dan memerlukan waktu yang lebih banyak untuk mahasiswa mencari video yang sesuai dan ditemukan juga kendala saat jaringan internet bermasalah, maka mahasiswa hanya menggambarkan konsep secara abstrak melalui presentasi lisan kepada mahasiswa lainnya. Menggunakan internet dalam pembelajaran memiliki kelemahan yaitu kurangnya instruksi yang jelas sehingga mahasiswa dapat mengakses apa saja tanpa ada validitas dari ahli. Oleh karena itu, mahasiswa dapat memperoleh konsep yang keliru (Mauludin, Sukamto, \& Muhardi, 2017). Selain menggunakan internet, mahasiswa juga menggunakan buku elektronik sebagai sumber belajar yang terungkap dari hasil analisis kebutuhan mahasiswa.

Hasil analisi angket kebutuhan mahasiswa menunjukkan bahwa sebagian besar mahasiswa lebih memilih berdiskusi dengan teman dibandingkan membaca buku saat mengalami kesulitan belajar. Penggunaan buku teks atau buku elektronik tanpa dilengkapi media pendukung cenderung membuat mahasiswa menjadi bosan. Hal tersebut juga diungkap oleh Mauludin et al. (2017) bahwa mahasiswa kehilangan motivasi saat belajar menggunakan buku teks tanpa dilengkapi video dan menyatakan ketidaksenangan mahasiswa membaca begitu banyak teks melalui layar. Dengan demikian, dibutuhkan suatu inovasi untuk mengembangkan buku teks yang dapat dilengkapi dengan media video atau gambar 3D sebagai contoh konkret untuk membantu mahasiswa memahami konsep. 
Salah satu cara mengatasi permasalahan tersebut yaitu dengan mengembangkan buku berbantuan teknologi augmented reality. Pendidikan merupakan bidang yang cocok untuk penerapan teknologi augmented reality. Alasan pemanfaatan augmented reality dalam dunia pendidikan yaitu mendukung interaksi antara lingkungan nyata dan virtual, penggunaan antarmuka yang serasa nyata untuk memanipulasi objek, kemampuan mentransmisikan secara halus lingkungan nyata dan objek virtual. Keunggulan tersebut memungkinkan augmented reality dapat diintegrasikan dalam bentuk buku untuk menghadirkan informasi yang lebih sehingga teks atau konten dalam buku tersebut tidak terlalu padat (Billinghurst, 2002). Selain dalam bentuk buku, pemanfaatan augmented reality untuk membuat model secara visual terkait sebuah mekanisme atau teori yang dianggap sulit. Misalnya, pemanfaatan augmented reality pada bidang Biologi dengan membuat struktur dan anatomi dari badan manusia. Animasi dalam bentuk 3D mampu mendemonstrasikan secara jelas tentang organ tubuh manusia sehingga pengajar dengan mudah menjelaskan mengenai materi tersebut (Lee, Owens, Francisco, \& Pfeiffer, 2004).

\section{SIMPULAN}

Berdasarkan hasil penelitian dapat disimpulkan bahwa mahasiswa membutuhkan bahan ajar cetak terintegrasi dengan teknologi yang dapat menampilkan gambar bergerak atau video untuk membantu mengatasi kesulitan mahasiswa dalam belajar. Pengembangan bahan ajar perlu dikembangkan sesuai dengan kebutuhan mahasiswa. Selanjutnya, peneliti mengembangkan bahan ajar yang didukung oleh teknologi sebagai media berupa teknologi Augmented Reality.

\section{DAFTAR RUJUKAN}

Azuma, R. T. (1997). A Survey of Augmented Reality. In Presence: Teleoperators and Virtual Environments, 6(4), $2792-2796$. https://doi.org/10.1039/c7ta11015d

Bachtiar, M. Y., \& Haryanto, H. (2015). Perancangan Aplikasi Berbasis Markerless Augmented Reality untuk Alat Peraga Organ Dalam Manusia pada Sekolah Menengah Atas. Seminar Nasional Teknologi Informasi dan Komunikasi Terapan (SEMANTIK), 63-66.

Billinghurst, M. (2002). Augmented Reality in Education. New Hirizons to Learning, 118(1). https://doi.org/10.1088/17426596/118/1/012049

Hernawati, D., \& Amin, M. (2017). Analisis Self Efficacy Mahasiswa melalui Kemampuan Presentasi di Kelas. Education and Human Development Journal, 02(April), 41-54.

Lee, W. W., Owens, D. L., Francisco, S., \& Pfeiffer, C. A. J. (2004). Book Review: Multimedia-Based Instructional Design: Computer-Based Training, Web-Based Training, and Distance Learning 2000. Online, (April), 91-93.

Mauludin, R., Sukamto, A. S., \& Muhardi, H. (2017). Penerapan Augmented Reality sebagai Media Pembelajaran Sistem Pencernaan pada Manusia dalam Mata Pelajaran Biologi. Jurnal Edukasi dan Penelitian Informatika (JEPIN), $3(2), 117$. https://doi.org/10.26418/jp.v3i2.22676

Mulyasa, E. (2003). Kurikulum Berbasis Kompetensi: Konsep, Karakteristik, dan Implementasi. Bandung: Remaja Rosdakarya.

Perrin, R. G., Perrin, E., Muirhead, B., \& Betz, M. (2015). The Pedagogical Functions of Arts and Cultural-Heritage Education with ICTs in Museums. International Journal of Instructional Technology and Distance Learning, $12(1), 7$.

Ponomariova, O. N., \& Vasina, O. N. (2016). Setting up the Interactive Educational Process in Higher Education. International Journal of Environmental and Science Education, 11(15), 8617-8627.

Ridwanulloh, A., Jayadinata, A. K., \& Sudin, A. (2015). Pengaruh Model Pembelajaran Contextual Teaching and Learning (CTL) terhadap Hasil Belajar Matematika. EduResearch- Raise The Standard, 1, 731-740.

Rifa'i, A. I. (2012). Efektivitas media pembelajaran CD E-Learning SMA Matematika Dilengkapi Metode Diskusi dan Presentasi terhadap Minat Belajar dan Berpikir Kritis Siswa. Disertasi tidak diterbitkan. UIN Sunan Kalijaga, Yogyakarta.

Setyosari, P. (2005). Media Pembelajaran. Malang: Elang Mas.

Smaldino, S. E., Lowther, D. L., \& Russell, J. D. (2008). Instructional Technology and Media for Learning. https://www.educatornetwork.com/Sites/PD/Professional Development/Educators/Courses/twt?lang=English

Suyono, H. (2012). Belajar dan Pembelajaran. Bandung: Remaja Rosdakarya.

Winarti, W. (2017). Contextual Teaching and Learning (CTL) untuk Meningkatkan Kemampuan Berpikir Kreatif Siswa. Jurnal Pendidikan Fisika dan Keilmuan (JPFK), 1(1), 1. https://doi.org/10.25273/jpfk.v1i1.4 